\title{
ISSUES OF LABOUR POTENTIAL GROWTH AND EFFECTIVE FORMATION OF EMPLOYMENT STRUCTURE IN UZBEKISTAN
}

\author{
MUYASSAR MIRZAKARIMOVA \\ Fergana polytechnic institute, Kirguli, Uzbekistan
}

\section{ABSTRACT}

This article studies how to bring the human labour potentials in compliance with the demand in labour market both qualitatively and quantitatively. Since the early years of the Independence a great attention is being paid to a human factor in Uzbekistan. A human potential is determined by such indicators as population size, their physical and intellectual, spiritual wellness and educational level. Society is related with labour potential growth, demographic processes, degree of public economic activeness. Due to expanded human reproduction, the amount of work resource is increasing. In the article the impact of demographic condition in Uzbekistan and training system of skilled personnel on labour market was analyzed. Such research methods as systematic approach, economic analysis, quantity, comparative and structural analysis were broadly used throughout the article.

\section{JEL CLASSIFICATION \& KEYWORDS}

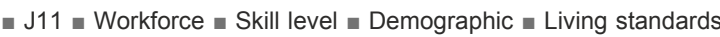
- Labour market

\section{INTRODUCTION}

It is well known that an individual and his scientific and educational ability is a key factor of social and economic development. The impact of human factor on labour effectiveness has been widely studied in economics. For example, Marshall A. researched the conditions related to people's physical, intellectual, spiritual welfare and power. [Marshall A, 1993. 268 page.] "This complies with great classification of labour productivity factors brought by Angel" and they are divided into these: a) "body", b) "intelligence" and c) "soul".

The term "labour force" is used to determine human involvement in economic processes. By labour force, human working potential is meant that is a complex of human's physical and intellectual potentials is widely understood and it can be utilized in production. In practice labour force is classified by such indicators as health, literacy and professionalism.

Today effective working conditions are classified as followings:

1. Psycho physiologic possibilities of involvement in socially useful activities,

2. exposure possibilities to adequate social communication,

3. possibilities to generate new ideas methods and imaginations,

4. rational morality,

5. knowledge and experience availability that needed to fulfil certain types of duties and works,

6. labour force supply in the market.

The above mentioned effective working conditions coincide with such labour factors as health, ability to work in groups, spirituality, creativity, literacy and professionalism levels and working hours. The indicators classifying those labour factors can apply to any human, to different labour unions, that is, to any employee and to whole population of the country.

www.journals.cz/
Human working potential is considered as one of his integrated personal potentials. In other words, toward to individual, human working potential is developed on the basis of his potentials given by the Creator and through education and life experience

\section{Potential of growth}

In accordance with the statement above, health is one the individual's working potential factors, without it one cannot carry out working process. In order to provide the continuity of working process it is necessary to generate work force on regular basis and for that reason, it is required to improve the individual's health.

According the definition of the World Health Organization (WHO) of health, it depicts it as a total physical and social peaceful condition. Peacefulness is dynamic condition of the mind classifying the spiritual harmony between the employees' potentials, needs, expectations and requirements and opportunities offered by the environment. In this definition it is stressed out to accept the health as subjective. In essence, it is all about human satisfaction from his life.

If we consider the definition of the WHO (total physical and social peaceful condition), more than $60 \%$ population of developed countries are not healthy. While it is hard to create labour forces in foreign countries, in this regard one can observe positive results in Uzbekistan. Tendency and process analysis of natural movement of population indicates certain positive changes in demographic development.

It is known that there are some problems with public health improvement in Uzbekistan. For example, in the Republic, death rate is rising $2,4 \%$ annually, including $3.1 \%$ and $2.3 \%$ in urban and rural places respectively. And this testifies for the above mentioned statement. Difference between those last two indicators is related with the age structure, that is, the share of aged people in the urban places is larger than that of the rural places. Death rate is rising, especially, because of aged people.

It is necessary to pay attention to two aspects of demographic problem solution. The first one is related with birth and high rate of child death, gender and dominance of young generation among population structure. The second one is related with the increasing number of population that capable to work and the job openings that not catching up with the former one. From the time reform launched to 2009 the population of Uzbekistan increased to 6 million 113 thousand and it was 27,1 million people as of January 1 , 2009.

At the present, the demographic situation of Uzbekistan is as following: an absolute birth number has declined by $6 \%$ in the Republic, $3.7 \%$ in urban; periods in years among births have increased; pregnancy after 35 years old has declined; migration has increased.

Today in the Republic the average childhood process has already been formed that began in the $90 \mathrm{~s}$ of the last century. [Khudoyberdiev, 2008, 70 p]. Because of birth increase the number of labour forces is climbing. (There 
exists numerical superiority of birth over death). In some regions migration is significantly affecting on the human resource size.

In the transition period to market relations the population of Uzbekistan is increasing whereas in some CIS countries such as Belorussia, the Ukraine and Kazakhstan the population is noticeably declining. Here the high relative coefficient of natural reproduction and the low relative coefficient of death remain. The process of switching from traditionally big families to middle size families is occurring. (Ata-Mirzaev, 2009. 164, 165, 177 pages).

An increasing economic activity of the population of Uzbekistan is depicted in the following table below. [Source: Data of the State Statistical Committee, the Republic of Uzbekistan].

According to table materials, in Uzbekistan 1991 through 2009 the labour resources increased to 5, 9 million people or by $57,8 \%$. This is equal to $57,9 \%$ of total population. In 2009 the number of total employed people was 11, 3 million that was $70,2 \%$ of labour forces. 2003 through 2009 the job security of labour resources increased at great rate.

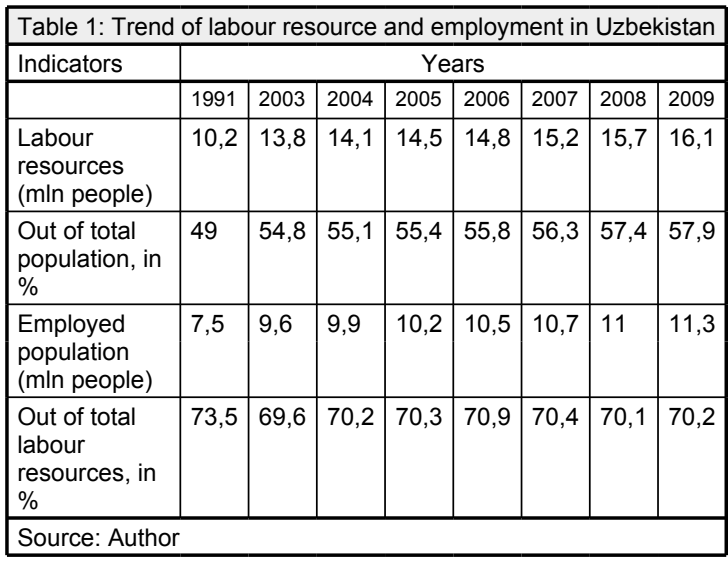

Ascending indicators of the increasing rural population and its great ratio in the total population of the Republic is a specific feature of demographic development of Uzbekistan. Beyond all, high birth ratio of the rural areas challenges the Government. Allowances for the big families, expansion of preschool and elementary education infrastructure, measures to offer wide range of public health services are directly concerned with birth rate.

It is known that on December 5, 2008 at a solemn meeting devoted to the $16^{\text {th }}$ anniversary of the Constitution adoption of the Republic of Uzbekistan, our president proclaimed 2009 year as a "Year of agricultural development and welfare". [I.Karimov, 2009, 62p.]. In frame of state program "Year of agricultural development and welfare" such measures are being taken to improve the housing conditions of rural population, provide rural places with water steadily, reconstruct roads and transportation system, develop services and service sphere in rural places, improve public health, save the health of females and children.

While the government ensures social protection stability and prevents society from drastically differentiate in the transition period, it also should get rid of "dependence" habit of big families that think it is possible to feed the family only by the state subsidies.

But in the market economy condition, hardships to earn a livelihood (mostly for the women) should not increase the www.journals.cz/ problems related with public health which is one of the integrated factors of labour potentials. It is to be regretted that such kind of lifestyle has come to Uzbek families. We should not forget that moral and social problems will derive from leaving children on their own because the husbands left for Russia with hope to make a better living and the wives went out to street for the same hope. In this regards, it is worth to mention that there is a big difference in meanings of "dependence" and "peace of mind". The word "dependence" implies the condition of indifference view toward to the future of his family, inaction to improve its financial, social and spiritual welfare.

The meaning of "peace of mind" is quiet different thing, that is, feeling satisfied by the health condition of himself and his family, by the degree he is enjoying peace, financial and mental welfares. In our opinion, currently at the active sections of society an insufficient degree of peace of mind is commonly observed. On the other hand, abundance of peace of mind more than enough may cause to worsen health and, in consequence, harm labour force at great degree.

At the present time, an implementation of high technologies in all fields of education is an important prerequisite for improvement of competitiveness and living standard. Social responsibility of high education is, at greater degree, to ensure each person to be demanded in the changing labour market, actively participate in changing innovation economy through which to get an opportunity to acquire specialty and skills that consequently will improve his and society's welfare.

Formation of market relations in Uzbekistan has changed the requirements for structures of specialist training, their knowledge and skill levels. Specialists who have edgecutting knowledge and able to comprehend innovation opportunities in certain fields of profession are of high demand now. Those specialists in demand are to be competent not only to solve production and operation matters but also to make right decisions

In Uzbekistan National Program of Personnel Training was adopted in 1997. It determined all directions and steps of reforms in all fields of education. But at the present, because the high education is firmly controlled by the government and lack of competitive environment is hindering to create effective stimulus and mechanisms to improve potentials of high education institutions

At the present, there are 71 high education institutions in Uzbekistan including their branch offices, 35 out of which are located in regions. [State Statistical Committee Data. The Republic of Uzbekistan]. 2008 through 2009 a total number of students enrolled at the universities were 297,9 thousand people. But the portion of full-time students against 10 thousand people of the country is remaining very low which is 108 now. The given ratio for Kazakhstan is 497, for Kyrgyzstan is 426 , for Moldavia is 338 , for Georgia is 355 . [CER Report on high education system, 2007].

In the Republic, 22 of high education institutions are specialized to train graduates for education sphere, 15 of them for industry, construction, transportation and communication, 5 of them for medicine, 4 of them for agriculture, 9 of them for economics and law, 7 of them for other branches. (Mirkurbanov, Anushkina, Danilova-Cross, 2009. 3 page).

Structural shift in the employee training derives from reforming of structural changes in secondary and specialized education and as well as reforming of agriculture, expansion of service sphere and the increasing 
demand for other new specialists. In spite of measures taken up to now in Uzbekistan, higher education institutes are falling behind to train skilled human resources in sufficient numbers that meet the new requirements of job market. According to the survey taken among the entrepreneurs, full satisfaction levels of graduate training of higher education institutions are as followings: $18,2 \%$ of economists, $18,6 \%$ of technical specialists, $17 \%$ of lawyers and $28,9 \%$ of Information Technology specialists. [Social Research: "Entrepreneurs of Uzbekistan: problems, insights, social portrait", CER, 2006]

In this condition, it is challenging to balance the demand in the labour market and the employment training. As a result, in social sphere branches (in such as public health, education) an inadequate number of staff to train the personnel is remaining. Insufficiency of engineers and technical specialists for the industrial enterprises and experienced managers for small businesses is currently observed. One of the quality indicators of population is employment allocation among industry branches. (Table 2)

According to the materials of the above figure, one can see that from 1995 to 2009 number of employed people in industry increased to 444 thousand. But the number of people employed within industry slightly increased, that is, by $0,7 \%$ from $12,9 \%$ in 1995 to $13,6 \%$ in 2009 .

In the independence years, the number of people employed in agriculture declined at great scale. From 1995 to 2009 the number of people employed in this branch of the national economy decreased to 524 thousand, its share in the whole employment data fell down by $15 \%$ (from $41,2 \%$ to $26,2 \%$ ).

The shares of such branches as construction, public health, physical culture and social protection, education, culture and art, science and scientific work increased in the total number of employment. At the period of current research the numbers of employed people in economy branches increased to: 436 thousand people in construction, 374 thousand people in public health, physical culture and social protection, 520 thousand I $n$ education, culture, art and science. Their increased shares in the total employment were $2,3 \%, 1,8 \%$ and $1,4 \%$ respectively.

One of the top priority directions of the compound reforms in Uzbekistan is to achieve the equilibrium of demand and supply of the labour forces and the stability of it. Structural shift in economy of the Republic is characterized by the surplus of perspective labour forces and the constraint of land and water resources. At the present, in all regions new manufacturing enterprises are being put into use and existing ones are being expanded. The Decree of the President of the Republic of Uzbekistan "On further measures of attracting of graduates of educational institutions to entrepreneurship" has played important role in stimulation of the youth employment in small businesses. After the adoption of the above mentioned legal provision and until recently, 34,404 graduates of the trade and craft colleges were employed by 14,248 small businesses. During that period more than 3,2 billion Uzbek soum worth privileged loans were offered to 1,207 graduates of the colleges to launch own businesses.

The state policies aimed at improving the labour market conditions devote to develop the economy branches that require small capital and advanced labour capacity. Textile, food processing industries and certain spheres of machinery fall into such kind of economy branches. From the point of demand stimulation for labour force and effective utilization of existing natural resources, further development of labour intensive branches is important. For this reason, in the Republic there are favourable conditions - raw materials and huge labour potential of highly skilled population. Structural policy in the agriculture, especially, through launching new small businesses, is aimed at redistributing people to other branches of economy. For example, in the villages new enterprises are being launched to process vegetables, corn, cotton and other agricultural products. The employment rate of rural people at the manufacturing infrastructure enterprises and people's workmanship that improve the effectiveness of the country's agricultural complex is rising. Getting people engaged in different types of home based businesses and supporting the family businesses are giving great results. In our Republic, small businesses are concentrating on labour-intensive businesses; therefore, they are a great source of new jobs.

Such features of small businesses as opportunities to create new jobs with small capital, chances to enter in a market niche that big business could not win and their favourable organizational structure to utilize small local resources highlight the importance of small business development.

Because of measures taken to improve small businesses, 8633,6 thousand people were employed in 2010 . This was equal to $74,4 \%$ of total employed people in economy. In

\begin{tabular}{|c|c|c|c|c|c|c|c|c|}
\hline & \multicolumn{8}{|c|}{ Years } \\
\hline & 1995 & 2003 & 2004 & 2005 & 2006 & 2007 & 2008 & 2009 \\
\hline Total & 8449 & 9589 & 9911 & 10196 & 10467 & 10735 & 11035 & 11328 \\
\hline in \%: & 100 & 100 & 100 & 100 & 100 & 100 & 100 & 100 \\
\hline \multicolumn{9}{|l|}{ out of total: } \\
\hline Industry & 12,9 & 12,8 & 13 & 13,2 & 13,4 & 13,5 & 13,5 & 13,6 \\
\hline Agriculture and forestry & 41,2 & 31,9 & 30,7 & 29,1 & 28,1 & 27,9 & 27,5 & 26,2 \\
\hline Construction & 6,3 & 8 & 8,2 & 8,3 & 8,4 & 8,5 & 8,5 & 8,6 \\
\hline Transportation and communication & 4,1 & 4,5 & 4,7 & 4,8 & 4,8 & 4,9 & 5 & 5,1 \\
\hline Trade and public catering, logistics and food processing & 8,3 & & 8,7 & 8,9 & 9,3 & 9,8 & 10,3 & 10,7 \\
\hline Household utility, non production types of personal services & 2,5 & 3 & 3 & 3,1 & 3,2 & 3,2 & 3,3 & 3,3 \\
\hline Public Health, Physical culture and social protection & 5,8 & 6,8 & 6,9 & 7,2 & 7,3 & 7,5 & 7,6 & 7,6 \\
\hline Education, culture and art, science and scientific work & 12,5 & 13,1 & 13,3 & 13,6 & 13,7 & 13,8 & 13,9 & 13,9 \\
\hline Finance, credit, insurance & 0,5 & 0,5 & 0,5 & 0,5 & 0,5 & 0,5 & 0,5 & 0,5 \\
\hline Others & 5,7 & 10,9 & 11 & 11,3 & 11,3 & 10,3 & 9,8 & 10,5 \\
\hline
\end{tabular}


particular, 6629.7 thousand people were self employed and 2003.9 thousand people were employed by the small enterprises. Cash revenues of employed people are developing especially, in small businesses.

Today the state policy devoted to deepening modern structural changes, renovating all aspects of society life will be a stimulus to carry out social projects that aimed at stabilizing our national economy and improving living standards.

The government is playing a leading role in all steps of currently implementing economic reforms that brought by the initiatives of the President of the Republic of Uzbekistan.

\section{Conclusion}

Having known the social, economic and demographic situation existing in Uzbekistan, we can conclude that today a great deal of attention is being paid not to the quantity of the people but to their quality. On the basis of the statements above, and to stimulate labour potential and form effective employment system in Uzbekistan we have come up with the following suggestions:

1. Regional employment programs should be developed on the basis of regional demographic processes, social and economic development levels and demand and need of existing enterprises.

2. Personnel training system should be improved in accordance with innovation processes of economy and its structural changes.

3. "Personnel improvement program" should be developed that is designed to train and re-train the employees in compliance with changing requirements of enterprises and innovation processes.

4. Local government bodies, employment agencies and human resource departments of the enterprises should develop steering system of measures to improve human potential.

\section{REFERENCES}

1. Karimov.I.A. Guaranteeing the country to develop gradually and steadily is our main aim. - Volume 17. Tashkent: Uzbekistan, 2009.

2. Ata-Mirzaev O.B. Population of Uzbekistan: history and the present. Tashkent: Social thought, 2009.

3. The Republic of Uzbekistan: State Statistic Committee. Collection of reports. Tashkent, 2009.

4. The Republic of Uzbekistan: The centre for economic research of the cabinet of ministers: Entrepreneurs in Uzbekistan: problems, thoughts, social portrait, Tashkent: 2006.

5. Mirkurbanov N, Anoshkina B and Danilova - Cross E. "High Education in Uzbekistan: condition and recommendations." Analytical note 1 (2009)

6. Khudoyberdiev Z.R. Labour market in the condition of transition period of economy: theory and practice. Tashkent: Finance, 2008.

7. Marshall. A. Principles of economic science. Moscow: Progress Firm Universe, 1993.

8. The Republic of Uzbekistan: The centre for economic research of the cabinet of ministers: Report on high education system, Tashkent: 2007. 